\title{
Oral Raft Forming In Situ Gelling System for Site Specific Delivery of Calcium ${ }^{\dagger}$
}

\author{
Manasa Moganti 1,* and Shivakumar H.N 2,* \\ KLE academy of higher education and research; \\ 2 Basic Science Research Center (Off Campus), KLE College of Pharmacy, Bengaluru 560 010, Karnataka, \\ India; \\ * Correspondence: manasamoganti37@gmail.com (M. M.); shivakumarhn@gmail.com (S. H. N.);
}

Received: date; Accepted: date; Published: date

Abstract: A single paragraph of about 100 words to give a brief introduction to your work.

Keywords: keyword 1; keyword 2; keyword 3 (List three to ten pertinent keywords specific to the article; yet reasonably common within the subject discipline.)

\section{Introduction}

Limitations of current oral conventional drug delivery systems of calcium

- The release of the drug is hindered by the fluctuation in gastric emptying time.

- The variation in $\mathrm{pH}$ in different segments of the gastro-intestinal tract.

- Difficulty of localizing an oral delivery system in a selected region of the GI tract.

- $\quad$ Resulting in side effects like constipation \& bloating of the stomach.

Gastroretentive Drug Delivery System

- Gastro-retentive drug delivery system (GRDDS) is an approach that has been used to resolve the bioavailability issues arising from poor absorption of nutrients or drugs that are absorbed only from a specific absorption window in the upper part of gastrointestinal (GI) tract.

- These systems are designed to be well retained in the upper part of the GI tract and release the drug in a sustained manner.

- $\quad$ The floating raft system (GFRS) is a novel GRDDS that would be well retained in the stomach by virtue of floating and bioadhesive properties.

- $\quad$ Biopolymers like sodium alginate, pectin and numerous others have been used to develop in situ gels as they offer advantages in development in terms of low cost, availability, biodegradation and freedom from toxicity and sustainability.

\section{Need for the Study}

- $\quad$ Oral calcium is the First line therapy for calcium deficiency.

- $\quad$ Approx. 75-100\% of Indians were Calcium deficient.

- Higher demand for sensitive group like children, pregnant \& PMS women, elderly patients.

\section{Justification for the Study}

- Calcium is primarily absorbed in the duodenum as a result of the presence of active absorption sites in the upper GI tract.

- Its solubility in acidic environment which enhances oral bioavailability makes it an ideal candidate for gastroretentive drug delivery system. 
We propose to undertake the "Oral raft forming in situ gelling system for site specific delivery of calcium".

\section{Methodology}

Conc. Range: $10-200 \mu \mathrm{g} / \mathrm{mL}$

Media: $0.1 \mathrm{~N} \mathrm{HCl}$

Instrument used: Flame photometer (Model-128, Systronics)

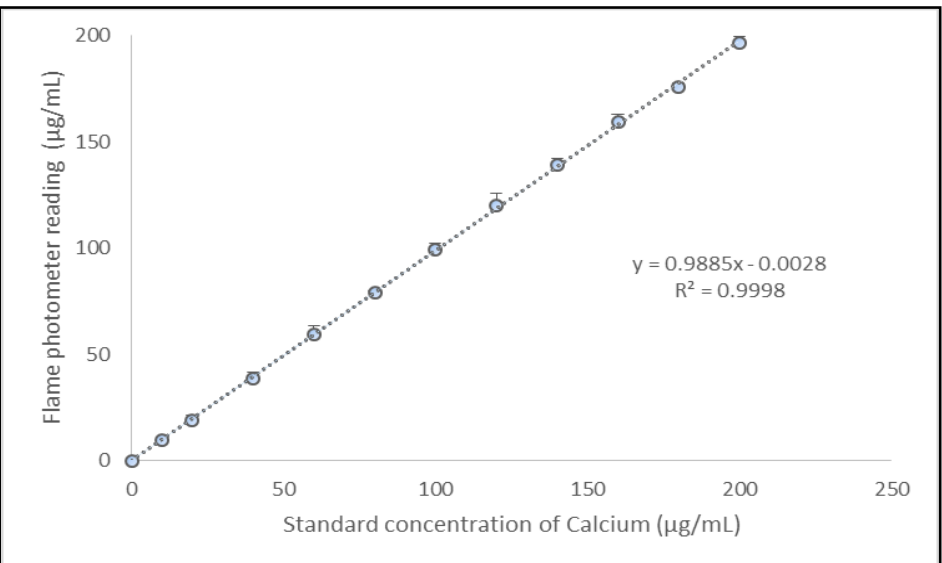

Figure 1. Calibration curve of calcium carbonate in pH 1.2.

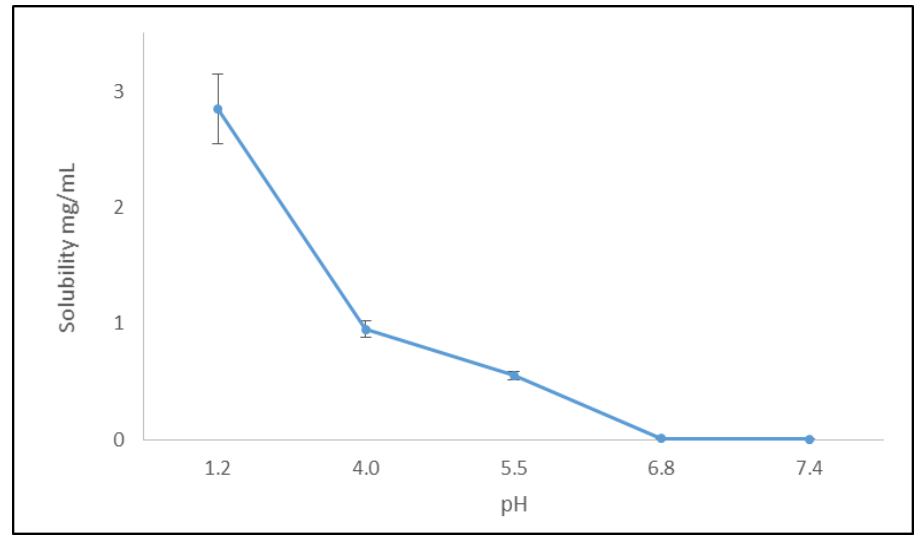

Figure 2. $\mathrm{pH}$ solubility profile of Calcium carbonate.

Buffers used:

(a) $0.1 \mathrm{~N} \mathrm{HCl}$

(b) $\mathrm{pH} 4.0$ Acetate buffer

(c) $\mathrm{pH} 5.5$ Acetate buffer

(d) $\mathrm{pH} 6.8$ Phosphate buffer

(e) $\mathrm{pH}$ 7.4 Phosphate buffer

Based on the Pourability and gelling properties on contact with the acidic environment the polymers and natural gums were screened during the preliminary trials.

Screening of the polymers for good gelation - The different viscosity grades of Sodium alginate, Hydroxypropyl methylcellulose like HPMC K4M, HPMC K15M, HPMC K100M.

Screening of the gums for controlled release-Xanthan gum, Guar gum, Karaya gum and Gellan gum. 


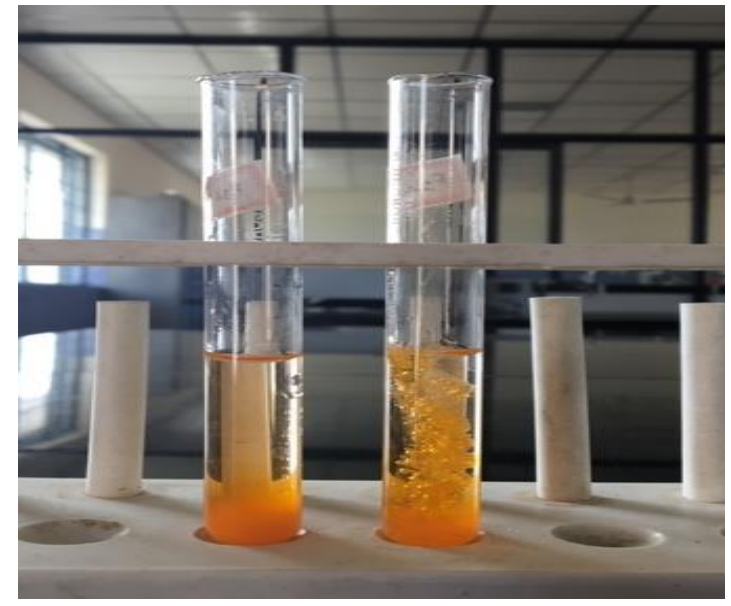

Preliminary studies

The following conclusion were drawn from the results of preliminary studies:

- when lower amounts of the polymer (X1: HPMC K100M) and higher amount of gum (X2: Xanthan gum) resulted in non pourable thick viscous solution

- when higher amounts of the polymer and lower amount of gum resulted bilayer tablets with increased floating lag times.

- The range of polymer to gum ratio was known to significantly affect the buoyancy lag times and dissolution of the raft forming solution.

A simple lattice design was employed to elucidate the influence of the factors namely the proportion of HPMC K100 M (X1) and Xanthan gum (X2) on the buoyancy lag time (Y1), percent release at the end of $1 \mathrm{~h}(\mathrm{Y} 2)$ and percent release at the end of $6 \mathrm{~h}(\mathrm{Y} 3)$.

Table 1. Independent variables with experimental ranges as per simplex lattice mixture design.

\begin{tabular}{|c|c|c|}
\hline Independent variables & Low value $(\%)$ & High value $(\%)$ \\
\hline X1 : Fraction of HPMC K100 M $(\% \mathrm{w} / \mathrm{w})$ & 50 & 90 \\
\hline X2 : Fraction of Xanthan gum $(\% \mathrm{w} / \mathrm{w})$ & 10 & 50 \\
\hline Dependent variables & \multicolumn{2}{|c|}{ Constraints } \\
\hline Y1: Buoyancy lag time (sec) & \multicolumn{2}{|c|}{ Minimize } \\
\hline Y2: Drug release at $1^{\text {st }}$ hr $(\%)$ & \multicolumn{2}{|c|}{ Minimize } \\
\hline Y3: Drug release at the end of $6^{\text {th }}$ hr $(\%)$ & \multicolumn{2}{|c|}{ Maximize } \\
\hline
\end{tabular}

Table 2. Formulation variables for the in situ gelling raft formulations and their observed responses.

\begin{tabular}{cccccc}
\hline Run & $\begin{array}{c}\text { X1: HPMC K 100 } \\
\text { M (\% w/w) }\end{array}$ & $\begin{array}{c}\text { X2: Xanthan } \\
\text { Gum (\% w/w) }\end{array}$ & $\begin{array}{c}\text { Y1: Buoyancy Lag } \\
\text { Time (s) }\end{array}$ & $\begin{array}{c}\text { Y2:\% } \\
\text { Release at 1 } \\
\mathbf{h}\end{array}$ & $\begin{array}{c}\text { Y3:\% } \\
\text { Release at 6 } \\
\mathbf{h}\end{array}$ \\
\hline F1 & 70 & 30 & $15.55 \pm 3.51$ & $21.78 \pm 2.47$ & $83.50 \pm 1.20$ \\
F2 & 50 & 50 & $4.52 \pm 2.78$ & $16.15 \pm 3.46$ & $68.65 \pm 0.97$ \\
F3 & 50 & 50 & $4.58 \pm 0.49$ & $14.51 \pm 3.06$ & $65.50 \pm 1.98$ \\
\hline F4 & 60 & 40 & $10.46 \pm 0.20$ & $25.12 \pm 1.80$ & $82.90 \pm 1.13$ \\
F5 & 80 & 20 & $34.43 \pm 2.39$ & $27.34 \pm 2.01$ & $87.07 \pm 0.85$ \\
\hline F6 & 90 & 10 & $56.17 \pm 3.62$ & $58.56 \pm 2.64$ & $80.33 \pm 1.68$ \\
\hline F7 & 90 & 10 & $50.74 \pm 0.44$ & $56.54 \pm 3.60$ & $79.30 \pm 0.04$ \\
F8 & 70 & 30 & $13.46 \pm 0.57$ & $19.54 \pm 3.30$ & $85.69 \pm 2.44$ \\
\hline
\end{tabular}




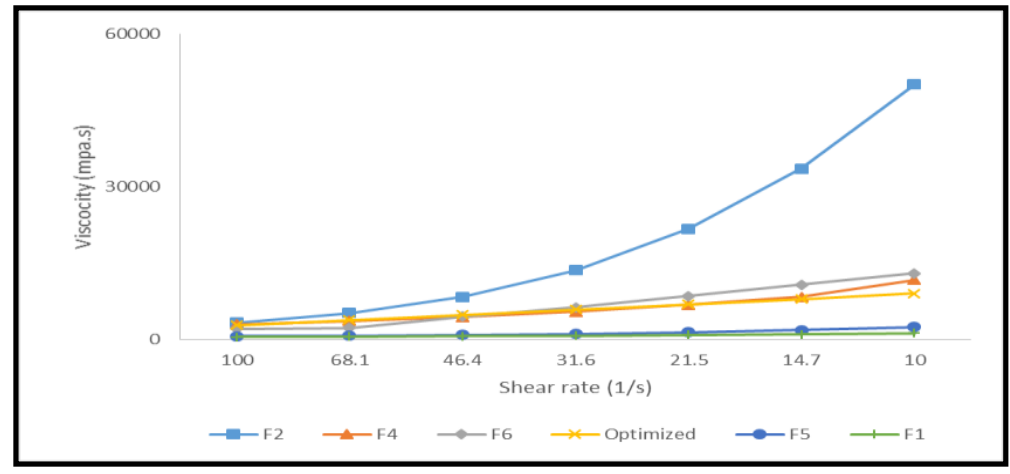

Figure 1. Overlay of Viscosity Curve (Viscosity versus Shear rate).

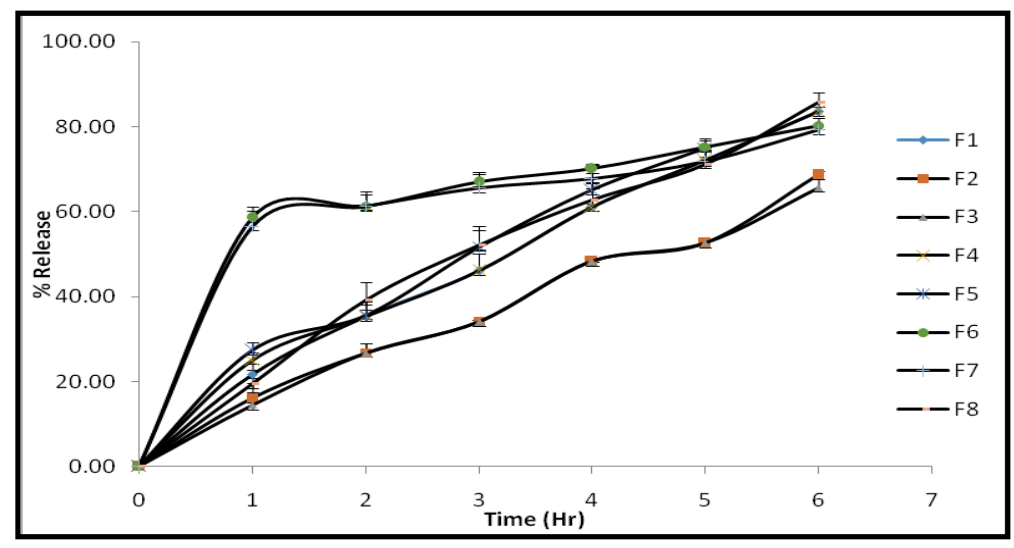

Figure 2. Comparative cumulative amount of Calcium carbonate release from in situ gelling raft formulation batches F1-F8.

Data Analysis of the D-Optimal Mixture Design

The design expert ${ }^{\circledR} \mathrm{v}-10$ software was used to systematically analyse the experimental data obtained and generate mathematical models that define the relationship between the proportions of the two components (X1 and X2) and the three responses namely buoyancy lag time (BLT), Rel $\mathrm{ln}_{\mathrm{h}}$ and Reloh.

Table 3. Summary of ANNOVA for the response parameters of the Model formulations of in situ gelling raft formulation prepared as per simplex lattice design.

\begin{tabular}{|c|c|c|c|c|c|}
\hline Response & F-Value & $p$-Value & $\mathbf{R}^{2}$ & $\operatorname{Adj} R^{2}$ & $\%$ C.V. \\
\hline Y1 & 395.04 & $<0.0001$ & 0.9850 & 0.9825 & 4.69 \\
\hline Y2 & 269.11 & $<0.0001$ & 0.9951 & 0.9914 & 5.44 \\
\hline Y3 & 52.54 & 0.0015 & 0.9546 & 0.9364 & 2.54 \\
\hline \multicolumn{6}{|c|}{ Regression equations of the fitted model containing only the significant terms: } \\
\hline \multicolumn{6}{|c|}{$\log B L T=+0.05^{*} X 1-0.01^{*} X 2$} \\
\hline \multicolumn{6}{|c|}{$\operatorname{Rel}_{1 \mathrm{~h}}=+1.36^{*} \mathrm{X} 1-8.94^{*} \mathrm{X} 2+0.16^{*} \mathrm{X} 1 \mathrm{X} 2$} \\
\hline \multicolumn{6}{|c|}{$\operatorname{Rel}_{6 \mathrm{~h}}=+0.67^{*} \mathrm{X} 1-0.92^{*} \mathrm{X} 2+0.03^{*} \mathrm{X} 1 \mathrm{X} 2$} \\
\hline
\end{tabular}

Buoyancy Lag time (Y1)

$\log B L T=+0.05^{*} \mathrm{X} 1-0.01^{*} \mathrm{X} 2$

- the effect of HPMC K100 M (X1) was found to have a positive effect on the BLT, this indicates that HPMC facilitated fluid movement into the liquid raft formulation through its swelling action, followed by expanding the surface of the raft gel.

- Xanthan gum (X2) was found to have a negative influence on the BLT, this implies low BLT are invariably associated with high levels of xanthan gum 


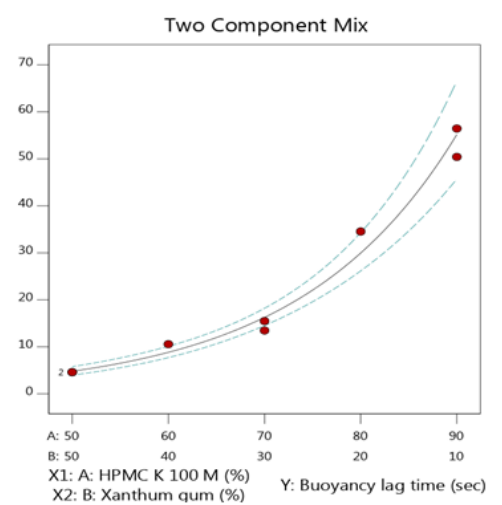

Figure 3. Two component mix for BLT.

Release at $1 \mathrm{~h}(\mathrm{Y} 2)$

$\operatorname{Rel}_{1 h}=+1.36^{*} \mathrm{X} 1-8.94^{*} \mathrm{X} 2+0.16^{*} \mathrm{X} 1 \mathrm{X} 2$

- the burst effect from the raft formulations could be minimized by using high levels of xanthan gum, could result in formation of more compact gel that would prevent the penetration of the dissolution media and therefore the burst effect.

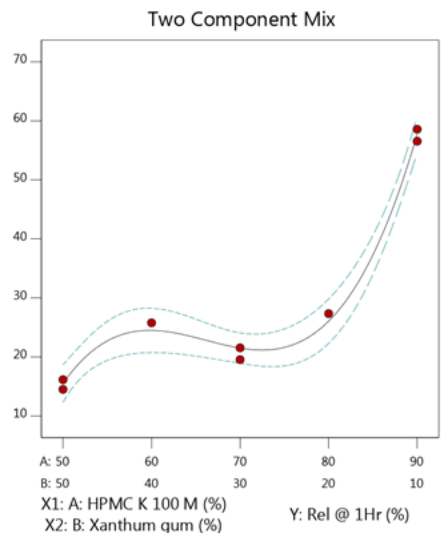

Figure 4. Two component mix for release at $1 \mathrm{~h}$.

Release at $6 \mathrm{~h}$

Rel $_{6 \mathrm{~h}}=+0.67^{*} \mathrm{X} 1-0.92^{*} \mathrm{X} 2+0.03^{*} \mathrm{X} 1 \mathrm{X} 2$

- amount of Xanthan gum (X2) had a high negative coefficient (-0.92) that implies the factor was found to have the considerable influence on the release at $6 \mathrm{~h}$. Xanthan gum on coming in contact with aqueous medium forms a very viscous strong gel network.

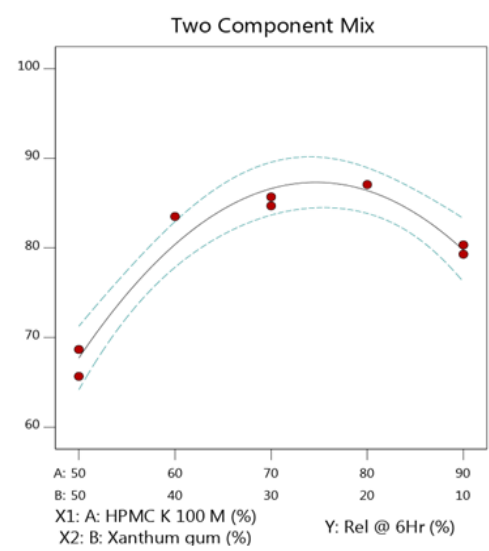

Figure 5. Two component mix for release at $6 \mathrm{~h}$. 


\section{Optimization}

A numerical optimization technique using the desirability approach was employed to develop new GRFS formulations with the desired responses.

Table 4. Composition of the optimized formulations and comparison of experimental values of the response parameters with the predicted values.

\begin{tabular}{cccc}
\hline Factor & \multicolumn{3}{c}{ Optimized Level (D-0.757) } \\
\hline X1:HPMC K 100 M & 65.88 & & \\
X2:Xanthangum & 34.13 & & \\
Response & Predicted value & Observed value & $\%$ Residual Error \\
Y1:BLT & 12.52 & 10.90 & 14.86 \\
Y2:Release at 1 h & 22.95 & 20.74 & -10.65 \\
Y3:Release at 6 h & 84.82 & 87.25 & -2.78 \\
\hline
\end{tabular}

\section{In Vivo X-ray Imaging Studies}

Study Title: In vivo X-ray Imaging Studies for different formulations in rabbit model.

Test Facility: Invivo Biosciences.

Study Number: IE-52.

Species \& Strain: Rabbit \& New Zealand white.

Avg. weight of animals: $2-2.5 \mathrm{~kg}$.

No. of groups: 2 (4 animals per group)

Group 1 (optimized batch of raft forming solution containing barium sulphate as a marker).

Group 2 (conventional suspension (Calcimax plus) containing the same marker).

Housing conditions: Standard laboratory conditions at $25 \pm 2{ }^{\circ} \mathrm{C}$ and $55 \pm 5 \% \mathrm{RH}$ with standard diet and tap water ad libitum.

X-ray machine: Skanray Model (Microskan DR).

Time intervals: $0,2,4$ and $6 \mathrm{~h}$.
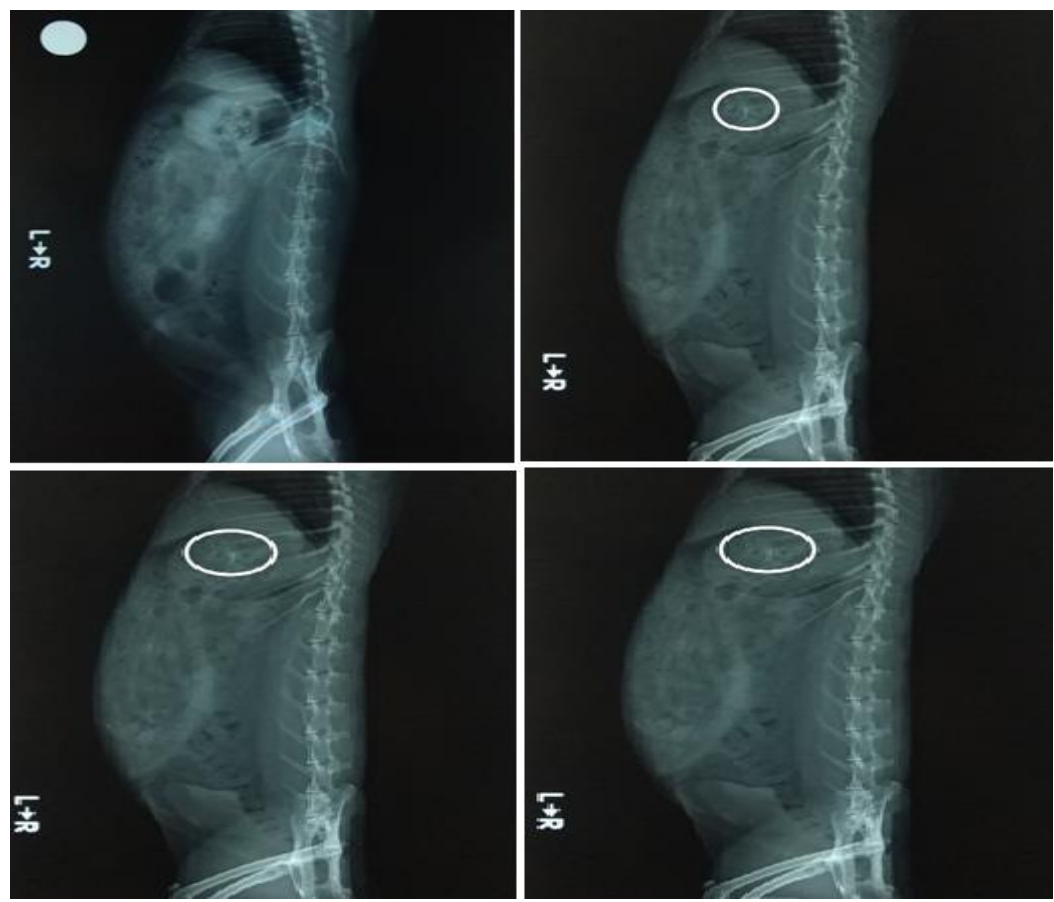


\section{Conclusions}

The studies collectively proved that bilayer gastroretentive tablets possessing floating properties would be highly promising drug delivery platform for nutrients and therapeutic agents with absorption window in the upper part of the gastrointestinal tract.

\section{References}

1. Nagaraju, B.; Ramu, B.; Saibaba, S.V.; Rajkamal, B. Formulation and evaluation of floating bioadhesive Doxofylline tablets. Int. J. Drug Deliv. 2016, 8, 134-141.

2. El-Zahaby, S.A.; Kassem, A.A.; El-Kamel, A.H. Formulation and in vitro evaluation of size expanding gastro-retentive systems of levofloxacin hemihydrate. Int. J. Pharm. 2014, 464, 10-18.

3. Yin, L.; Qin, C.; Chen, K.; Zhu, C.; Cao, H.; Zhou, J.; He, W.; Zhang, Q. Gastro-floating tablets of cephalexin: Preparation and in vitro/in vivo evaluation. Int. J. Pharm. 2013, 452, 241-248.

4. Arza, R.A.K.; Gonugunta, C.S.R.; Veerareddy, P.R. Formulation and Evaluation of Swellable and Floating Gastroretentive Ciprofloxacin Hydrochloride Tablets. AAPS PharmSciTech 2009, 10, 220-226.

Publisher's Note: MDPI stays neutral with regard to jurisdictional claims in published maps and institutional affiliations.

(C) 2020 by the authors. Submitted for possible open access publication under the terms and conditions of the Creative Commons Attribution (CC BY) license (http://creativecommons.org/licenses/by/4.0/). 